\title{
Assessment of Genetic Diversity in Various Yield Traits to Determine a High Yielding New Type of Upland Rice
}

\author{
Reny Herawati ${ }^{\mathrm{a},}{ }^{,}$, Alnopri ${ }^{\mathrm{a}}$, Masdar ${ }^{\mathrm{a}}$, Usman Kris Joko ${ }^{\mathrm{a}}$, Bambang Gonggo Murcitro ${ }^{\mathrm{b}}$ \\ ${ }^{a}$ Department of Crop Production, Faculty of Agriculture, University of Bengkulu, Bengkulu, 38371, Indonesia \\ ${ }^{b}$ Department of Soil Science, Faculty of Agriculture, University of Bengkulu, Bengkulu, 38371, Indonesia
}

Corresponding author: *reny.herawati@unib.ac.id

\begin{abstract}
This experiment's objective was to estimate the genetic diversity of F5 populations on various yield components for developing high-yielding upland rice. The experiment was carried out from April to August 2018 at Semarang Village, Bengkulu, Indonesia. Plant materials used in the experiment were 160 accessions of $\mathrm{F} 4$, obtained from a pedigree selection of crossing between two local landraces (Sriwijaya and Bugis) and two introduced accessions (IR-148 and IR-7858-1). The experiment was arranged in Augmented Design with a spaced planting system $(20 \times 20 \mathrm{~cm})$. The variance between populations was determined by Principal Component Analysis (PCA) with XLSTAT version 9.0. Broad sense genetic diversity was found for the number of traits, such as number of panicles, the total number of grains per panicle, number of empty grains per panicle, number of filled grain per panicle, percentage of empty grain, the weight of 1000 grains, the weight of grain per hill, which potentially improved high yielding. These genotypes were categorized into three groups. Group I showed superior traits for the total number of grains per panicle, the number of filled grain per panicle, weight of 1000 grains, and weight of grain per hill found in genotypes BKL4-B-2, BKL3-B-3, BKL4-B-3, BKL3-B-2. Group II had superior traits for panicle length, the number of empty grains per panicle, and the percentage of empty grain were BKL1-RS*1-3, BKL1-RS*1-1, BKL3-RS*1-1, BKL3-RS*1-3, BKL1-RS*1-2, BKL2-RS*1-2, and BKL2-RS*1-1. Groups III was superior to the number of panicle traits found in genotypes BKL2-B-2, BKL3-B-1, BKL1-B-1, BKL1-B-2, and BKL2-B-1.
\end{abstract}

Keywords - Genetic diversity; PCA analysis; high yielding; upland rice.

\section{INTRODUCTION}

The contribution of upland rice to the national rice production in Indonesia has been remarkably insignificant. Its productivity is only 2.5 ton.ha $^{-1}$, much lower than that of lowland rice, reaching 5.15 ton.ha $^{-1}$ [1]. However, as the land for growing lowland rice has become limiting, increasing national rice production must be done by growing upland rice at the upland soil, because of which improves the performance of upland rice has always been of paramount importance.

Many factors contribute to the low productivity of upland rice, such as an unfavorable environment, improper crop management, and lack of high-yielding seeds [2], [3]. One way to cope with those problems is by developing a highyielding new type of upland rice adaptive to such environmental conditions. Assembling a high-yielding and drought-tolerant rice variety may be done by combining all the excellent traits of two parental lines, like high yield and tolerance to drought. The parental lines come from local landraces or introduced accessions, having desirable-superior traits [4], [5]. An ideal new type of high-yielding rice paddy is expected to increase the potential yield, which is in line with the Indonesian government's program so-called food selfsufficient program.

Assembling a new variety of upland rice may start by crossing two or more parental lines to incorporate the expected superior traits within a new population. The population is then selected, evaluated, tested for its environmental adaptability to get a promising line ready to be released as a new high-yielding variety. Selection is an effective method to obtain the essential traits, having a high chance of succeeding. If a specific trait has high genetic diversity, it must have a high intergroup diversity so that a selection process will be easier to get the expected traits. Thus, it is essential to have information on the genetic diversity of a population to get an expected new variety. The trait variability of plants significantly determines the yield potency and improves the efficiency of using the genetic materials in the breeding program for increasing yield [6], [7], [8]. 
Trait superiority must be prioritized during the new variety program's assembly so that each promising variety owns a specific trait different from the existing variety. A specific trait identity must be identified thoroughly to prevent duplication and ensure the newly released variety's identity. A selection process will be effective, provided that the targeted traits have a high value of heritability. Heritability is essential to determine the choice of a selection method and how generation selection of the expected trait should be made [9].

Genetic advance reflects how effective the selection process was taking place. A selection process will be effective provided that the value of genetic advance is high and supported by a high value of heritability. Furthermore, heritability value also determines the selection progress, in which the higher the heritability values, the higher the selection progress will be, and the faster a high-yielding variety will be obtained. Genetic diversity plays an essential aspect in which breeders always work [10], [8], [11], [12].

Principal component analysis might be used to determine trait diversity and to identify the general trait, while biplot visualization can determine the specific trait of a particular genotype ([13],[14]). This experiment's objective was to identify the agronomic characters and estimate the genetic diversity of F5 populations on various yield component varieties and trait quality for developing high-yielding new types of upland rice.

\section{MATERIALS AND METHOdS}

The experiment was carried out from April to August 2018 at Semarang Village, Bengkulu City, Bengkulu Province, Indonesia. Plant materials used in the experiment were 160 accessions of F4 Generations, obtained from a pedigree selection of crossing between two local landraces (Sriwijaya and Bugis) and two introduced accessions (IR-148 and IR7858-1).

The experiment was arranged in Augmented Design with a spaced planting system $(20 \mathrm{~cm} \times 20 \mathrm{~cm})$. Each accession was planted in six rows with one seed per hole using a head-torow system (about 800 population). At ten days after planting (DAP) the crops were fertilized with $150 \mathrm{~kg}$. ha-1 Urea, 100 $\mathrm{kg}$. ha- $\mathrm{hP}^{-1}$ S6, and $100 \mathrm{~kg}$. ha-1 $\mathrm{KCl}$. At 30 DAP the crops were fertilized with $100 \mathrm{~kg}$. ha- ${ }^{-1}$ Urea, $100 \mathrm{~kg}$. ha- ${ }^{-1}$ SP36, and $100 \mathrm{~kg}$. ha ${ }^{-1} \mathrm{KCl}$. Pests, diseases, and weeds were managed intensively. Variables measured included length of panicle, number of panicles per hill, number of total grains per panicle, number of filled grain per panicle, percentage of empty grain per panicle, the weight of 1000 grains, and weight of filled grain per hill.

\section{A. Data Analysis}

Data were analyzed with Microsoft Excel Statistical Program combined with Minitab 15. Principal Component Analysis (PCA) determined the variance between populations, correlation matrix, and biplot with XLSTAT version 9.0.

\section{B. Estimating Variance Component and Heritability}

Data were analyzed for estimating the value of phenotype variance $\left(\sigma^{2} \mathrm{p}\right)$, genetic variance $\left(\sigma^{2} \mathrm{~g}\right)$, the variance of the environment $\left(\sigma^{2} \mathrm{e}\right)$, coefficient of genotypic diversity (CGD), the standard deviation of genotypic variance $\left(\sigma \sigma^{2} \mathrm{~g}\right)$, and broad sense of heritability (hbs) were measured with the following Formula:

$$
\operatorname{Varian}(\sigma 2)=\frac{\left\lceil\sum\left(x i-x^{2}\right)\right\rceil}{n-1}
$$

Phenotype variance $\left(\sigma^{2} \mathrm{p}\right)=\sigma^{2} \mathrm{~F}$

$$
(\sigma 2 e)=\frac{\sigma 2 \mathrm{P} 1+\sigma 2 \mathrm{P} 2}{2}
$$

Variance of environment

Genetic variance $\left(\sigma^{2} g\right)=\sigma^{2} p-\sigma^{2} e$

$$
\text { Heritability }(h b s)=\frac{\sigma 2 g}{\sigma 2 p}
$$

We categorized heritability values based on [15] criteria, which were high when $h_{b s}$ were $\geq 0.50$, medium $0.20>$ $\mathrm{h}_{\mathrm{bs}}>0.50$, and low $\mathrm{h}_{\mathrm{bs}} \leq 0.20$. The CGD values were used for estimating how broad the genetic variance own by each trait estimated based on the following Formula [16]:

$$
C G D=\frac{\sqrt{\sigma 2 g}}{X} \times 100 \%
$$

Where, $\sigma^{2} \mathrm{~g}=$ genetic variance, $\mathrm{x}=$ population mean. Criteria: narrow (0-10\%), medium (10-20\%), and broad ( $>20 \%)$.

The following Formula could determine the value of genetic gain (GG):

$$
\begin{gathered}
\mathrm{GG}=\mathrm{S} . \mathrm{h} 2 \mathrm{bs} \\
\mathrm{GG}(\%)=\mathrm{Gx} 100 \% \\
\mathrm{X}
\end{gathered}
$$

where $\mathrm{S}=$ selection differential, $\mathrm{G}=$ selection advance, $\mathrm{G}(\%)$ $=$ genetic gain in percentage, $\mathrm{h} 2 \mathrm{bs}=$ broad sense heritability, $\mathrm{X}=$ average of initial population. Selection was done for selected individual from single trait at $10 \%$ of intensity.

\section{RESULTS AND DISCUSSION}

\section{A. Genetic Diversity of F5 Population}

The estimated value of plant genetic trait showed that the coefficient of genetic diversity (CGD) ranged between 7.63\% and $62.46 \%$. The lowest CGD value $(7.63 \%)$ was found in the panicle length trait, while the highest value was found in the percentage of emptied grain per panicle $(62.46 \%)$. The absolute value of CGD $(0-62.46 \%)$ was then used to decide the relative value of CGD, in which $62.46 \%$ was assumed to be the $100 \%$ relative value. Therefore, the criteria for absolute value transformed to low $(0.0 \%<\mathrm{x}<15.62 \%)$, medium-low $(15.62 \%<x<31.23 \%)$, medium-high $(31.23 \%<x<46.85 \%)$, and high $(46.85 \%<\mathrm{x}<62.46 \%)$.

Traits having a low and medium-low of CGD values were categorized as traits with narrow genetic diversity. In contrast, traits having medium-high and high CGD values were categorized as traits with broad variability ([17],[18]). Based on those criteria, we found that the panicle's length is a trait with narrow genetic variability while the number of panicles, total grain per panicle, and empty number grain per panicle as traits with medium broad genetic variability.

Furthermore, the number of filled grain per panicle, percentage of empty grain per panicle, weight of 1000 grains, and weight of grain per hill were categorized as traits with broad genetic variability. In other words, there was one trait that has low genetic variability and seven traits having broad genetic variability, having the chance to improve the genetic 
performance of the rice through the following traits: number of panicles, number of total grains per panicle, number of empty grains per panicle, number of filled grain per panicle, percentage of empty grain, the weight of 1000 grain, and weight of grain per hill. A broad genetic variability means that the selection processes of the trait run effectively and be able to improve the genetic traits for the following generation ([19],[8]). The selection process could be done in a more convenient way for traits with broad genetic variability that can be used for crop improvement.

TABLE I

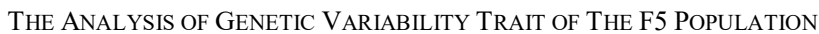

\begin{tabular}{lllllllll}
\hline Characters & $\boldsymbol{\sigma}^{\mathbf{2}} \mathbf{g}^{*}$ & $\boldsymbol{\sigma}^{\mathbf{2}} \mathbf{p}$ & $\mathbf{C G D}(\boldsymbol{\%})$ & Criteria & $\mathbf{h}_{\mathbf{b s}}$ & Criteria & GG & GG\% \\
\hline Panicle length & 4.46 & 5.70 & 7.63 & narrow & 0.78 & high & 2.91 & 13.27 \\
Number of panicles & 350.88 & 352.20 & 30.21 & moderate & 0.99 & high & 32.84 & 89.67 \\
Total number of grains per panicle & 2942.34 & 3025.00 & 25.51 & moderate & 0.97 & high & 92.86 & 84.57 \\
The number of fill grains per panicle & 2588.42 & 2669.15 & 30.09 & broad & 0.97 & high & 86.83 & 59.39 \\
The number of empty grains per panicle & 31.93 & 33.04 & 17.70 & moderate & 0.97 & high & 9.61 & 26.24 \\
Percentage of empty grain per panicle & 159.74 & 162.58 & 62.46 & broad & 0.98 & high & 21.86 & 57.56 \\
1000 weight grains & 4889.26 & 4890.58 & 43.43 & broad & 1.00 & high & 123.03 & 335.88 \\
Grain weight per hill & 1019.49 & 1021.41 & 51.49 & broad & 0.99 & high & 56.09 & 153.13 \\
\hline${ }^{*} \sigma^{2} g=$ genetic variance; $\sigma^{2} p=$ phenotype variance; $C G D=$ Coefficient Genetic Diversity, $h_{b s}=$ broad sense heritability; GG=genetic gain
\end{tabular}

The estimated value of trait heritability was 0.78 for panicle length and 1.0 for the weight of 1000 grain (Table 1.). Based on [15] criteria, the estimated heritability values of all traits were high. However, the high genetic advance was found only for the total number of grains per panicle, the number of filled grain per panicle, weight of 1000 grain, weight of grain per hill. Traits that have high heritability determine the effectivity of the selection process and speed up the advance of crop improvement. High heritability values suggested that genetic factors are more dominant than the environmental factors, and that selection process could be done in the early generation [20], [21], [7].

\section{B. Lines Performance of F5 Population}

The panicle length produced in this experiment ranged from 24.22 to $31.04 \mathrm{~cm}$, with $27.91 \mathrm{~cm}$ on average (Table 2.).

TABLE II

The Minimum, MaXimum, AVERAge Values, And Standard DeViation OF YIELD COMPONENT OF THE F5 POPULATION.

\begin{tabular}{lllll}
\hline Characters & Min & Max & Mean & SD* \\
\hline Panicle length & 24.22 & 31.04 & 27.91 & 1.44 \\
$\begin{array}{l}\text { Number of panicles } \\
\text { Total number of }\end{array}$ & 3.00 & 27.00 & 12.46 & 7.18 \\
$\begin{array}{l}\text { spikelet/panicles } \\
\text { fill grain/panicle }\end{array}$ & 141.00 & 307.42 & 214.35 & 47.17 \\
$\begin{array}{l}\text { Empty grain/panicle } \\
\text { Percentage of empty }\end{array}$ & 20.07 & 109.25 & 47.92 & 27.59 \\
grain & 7.54 & 46.65 & 22.01 & 11.07 \\
$\begin{array}{l}\text { 1000 grains weight } \\
\text { Grains weight/hill }\end{array}$ & 26.84 & 55.52 & 40.74 & 6.93 \\
\hline SD=Standard deviation & 21.45 & 121.99 & 59.55 & 30.56 \\
\hline
\end{tabular}

The lines obtained from the hybridization produced lines with the shortest panicle $(24.22 \mathrm{~cm})$ and the longest panicle $(31.04 \mathrm{~cm})$. Some lines, however, showed shorter panicle than their parental lines. The length of the panicle is strongly correlated to the number of grains per panicle. The number of panicles ranged from 3.00 to 27.00 , with an average of 12.46 . To improve the potential yield of $10 \%$ higher than New Plant Type (NPT), some traits are needed, such as 330 panicles per $\mathrm{m}^{2}$ and 150 grain per panicle, 22 ton per hectare of biomass (with $14 \%$ of moisture content), and $50 \%$ harvesting index [22], [23]. A strategy has been developed for getting a new type of rice with specific panicle traits and 150 grains per panicle [23]. The number of panicles per $\mathrm{m} 2$, percentage of filled grain, total biomass, and harvesting index are needed for developing the new type of rice [24].

The lines obtained from the crossing demonstrated the number of grains per panicle up to $141.00-307.42$, with 214.35 on average, the highest number of the filled grain of 268.75 with 166.43 in average, and the low percentage of empty grain (22.01\%), as shown in Table 2. Poor grain filling is caused by the low level of apical dominance at the panicle, the poor arrangement of grain on the panicle, and the limiting activity of phloem in transporting assimilates [24]. Furthermore, the inefficient partition of assimilates causes the new rice paddy's poor grain filling [25].

The NPT rice in Indonesia must have the reasonable number of the tiller (12-18 tiller) [26]. However, all of them must be productive, with the number of grains per panicle up to $150-250$, percentage of the filled grain of $85-95 \%$, the weight of 1000 grain about 25-26 g, short but vigorous stem $(80-90 \mathrm{~cm})$, and early season (110-120 days). With those traits, the newly bred rice paddy is expected to yield 9-13 tons per hectare. The population of the F5 line demonstrated a high number of grain $(307.42,214.35$ on average), a low percentage of empty grain $(22.01 \%)$, and a high percentage of fille grain $(268.67,166.43$ on average) per panicle. In short, these lines were the potential for producing high yield because they demonstrated the high number of panicles per hill, 12.46 on average (Table 2.). The previous study recommended avoiding an extreme trait when obtaining newly breed rice paddy, such as a high number of grain (200-250) per panicle leading to the poor grain filling, because of which IRRI set a standard for 150 grain per panicle to ensure a high percentage of filled grains [24]. Besides, the weight of 1000 seeds of the new lines produced in this experiment was about 26.84-55.52 
$\mathrm{g}$, with an average of $40.74 \mathrm{~g}$. Ideally, a new variety must weigh 26.84-55.52 $\mathrm{g}$ for 1000 seeds [27]. Therefore, all newly bred lines resulting in this experiment were considered to have a high potential yield based on this standard. To increase the yield of newly bred rice, one needs to have parental lines having long panicles and a high number of grain per panicle ([28],[24]). Also, recommended by [27] that an ideal new variety has $180-240$ grain per panicle, and $85 \%$ of the grain is fully filled.

\section{Correlation and Analysis of Principal Component between Yield Component and Yield}

The correlation values could determine the relationship between the yield component and yield. The correlation between characters was presented in Table 3. Panicle length was negatively correlated to and significantly different from the number of panicles (-0.59) and weight of grain per hill ($0.49)$, and positively correlated with and significantly different from the number of empty grains per panicle (0.64) and percentage of emptied grain $(0.57)$

TABLE III

COEFFicient of CORRELATIONS BETWEen AgronomicAl CHARACTERS AND GRAin YiELD PER TILLER

\begin{tabular}{lllllllll}
\hline Characters & PL & NP & NSP & FGP & EGP & PEG & $\mathbf{1 0 0 0 G W}$ & GW \\
\hline PL & $\mathbf{1}$ & $\mathbf{- 0 . 6 *}$ & 0.21 & -0.17 & $\mathbf{0 . 6 4 *}$ & $\mathbf{0 . 5 7 *}$ & -0.18 & $\mathbf{- 0 . 4 6 *}^{*}$ \\
NP & & $\mathbf{1}$ & -0.28 & -0.04 & -0.40 & -0.37 & 0.09 & $\mathbf{0 . 4 2 *}$ \\
NSP & & & $\mathbf{1}$ & $\mathbf{8 2 *}$ & 0.35 & 0.02 & $\mathbf{0 . 4 5 *}$ & 0.33 \\
FGP & & & & $\mathbf{1}$ & -0.25 & $\mathbf{- 0 . 5 4 *}$ & $\mathbf{0 . 6 6 *}$ & $\mathbf{0 . 6 8 *}$ \\
EGP & & & & & $\mathbf{1}$ & $\mathbf{0 . 9 3 *}$ & -0.33 & $\mathbf{- 0 . 5 6}^{*}$ \\
PEG & & & & & & $\mathbf{1}$ & $\mathbf{- 0 . 5 0 *}$ & $\mathbf{- 0 . 7 3 *}$ \\
1000 GW & & & & & & & $\mathbf{1}$ & $\mathbf{0 . 7 9 *}$ \\
GW & & & & & & & & $\mathbf{1}$ \\
\hline
\end{tabular}

*Values in bold are different from 0 with a significance level alpha $=0.05 ; P L=$ Panicle length;NP= Number of panicles; FGP $=$ fill grain/panicle; EGP $=$ empty grain/panicle; $P E G=$ Percentage of empty grain; $1000 G W=1000$ grains weight; $G W=$ Grains weight/hill

Number of panicles, number of filled grain, and weight of 1000 grains positively correlated to and significantly different from grain per hill weight. Consequently, those three traits could be used as selection criteria for increasing grain yield. The weight of 1000 grain is correlated to the size and degree of fullness of the grain. The high percentage of filled grain and the enormous size of grain lead to the high weight of 1000 grain (Table 3). The increase of the number of filled grain per panicle leads to the increase of the number of grains per hill significantly.

In contrast, increasing the number of empty grains per panicle reduces grain yield per hill. The high number of filled grain per panicle, combined with a high percentage of filled grain per panicle, will significantly increase grain yield per hill. The grain filling in compact-panicle rice becomes poor subject to an expression of the recessive allele for high ethylene production, but the allele is amenable for suppression by the corresponding dominant allele [29].

The results of principal trait analysis showed that some traits significantly affected the variability of the tested lines. The results significantly reduced total morphological traits evaluated to three main components (KU-1, KU-2, and KU3 ), which represented the eigenvalue of $>1$ and the variability of line performance up to $88.15 \%$ (Fig 1). Moreover, the trait with a higher coefficient value of the main component contributes to the main component [30].

Eigenvalue contributed significantly to total diversity. The first principal component (KU-1) with an eigenvalue of 3.96 contributed to $49.47 \%$ of total diversity. The second principal component (KU-2) with an eigenvalue of 2.33 contributed to $78.53 \%$ of total diversity among the tested lines, and the third component (KU-3) with an eigenvalue of 0.77 contributed to $88.15 \%$ of the total diversity of the lines tested.

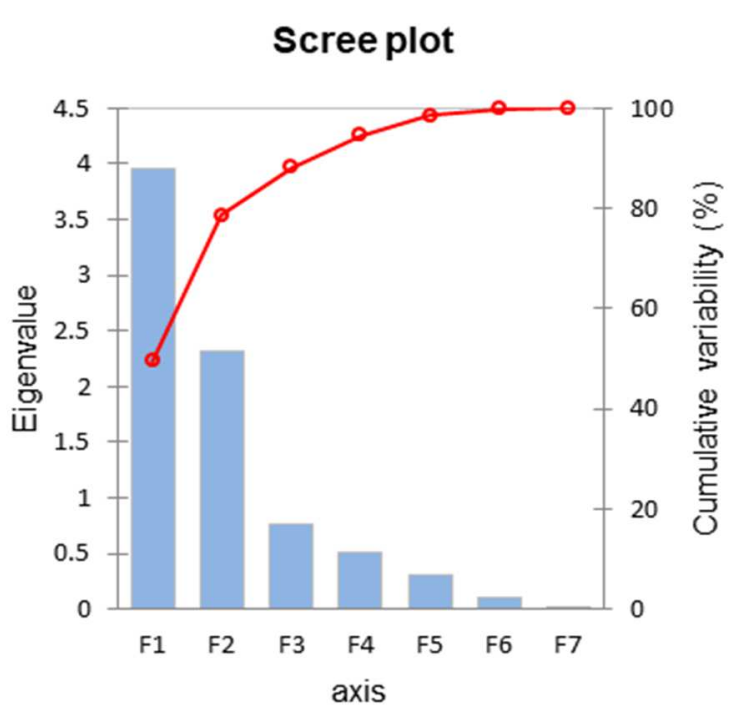

Fig 1. The eigenvalue for the main components and their contribution to total diversity and cumulative diversity

\section{Morphological Characters Main Component}

Analysis of the identifier vector shows which trait contributes maximally to the diversity of the tested lines (Table 4), as the trait with the highest point of identifier vector and positive value. For $\mathrm{KU}-1$, the traits contributing to the diversity of tested lines included length of panicle, number of filled grain per panicle, number of empty grains per panicle, percentage of empty grain, the weight of 1000 grain, and weight of grain per hill. Besides, it was found in the number of total grains per panicle for KU-2 and the number of panicles for KU-3.

TABLE IV

IDENTIFIER VECTOR FOR YIELD COMPONENT TRAITS CONTRIBUTING TO THE DifFERENCES OF THE Tested Lines of THE F5 Population 


\begin{tabular}{llll}
\hline \multirow{2}{*}{ Morphological Characters } & \multicolumn{3}{l}{ Main Components } \\
\cline { 2 - 4 } & KU1 & KU2 & KU3 \\
\hline Panicle length & $\mathbf{0 . 4 2 4 *}$ & 0.250 & 0.057 \\
Number of panicles & 0.223 & 0.305 & $\mathbf{0 . 3 8 8}$ \\
Total number of spikelet/panicles & 0.048 & $\mathbf{0 . 8 4 6}$ & 0.049 \\
fill grain/panicle & $\mathbf{0 . 4 8 1}$ & 0.436 & 0.000 \\
Empty grain/panicle & $\mathbf{0 . 6 0 0}$ & 0.232 & 0.158 \\
Percentage of empty grain & $\mathbf{0 . 8 1 7}$ & 0.037 & 0.102 \\
1000 grains weight & $\mathbf{0 . 5 2 9}$ & 0.192 & 0.000 \\
Grain's weight/hill & $\mathbf{0 . 8 3 7}$ & 0.029 & 0.016 \\
\hline *Values in bold are significantly different on $p$-value $=1 \%$ or $p$-value $=5 \%$.
\end{tabular}

The contribution of diversity explaining the indicators used to observe the relationship between yield potency and yield was $100 \%$. However, by conducting biplot analysis, which reduced all the indicators into two-side dimensions, the information that could be explained was only about $78.53 \%$, meaning that the information that could be explained by biplot analysis was $>70 \%$. It meant that biplot analysis has already represented enough information on the relationship among those eight indicators.

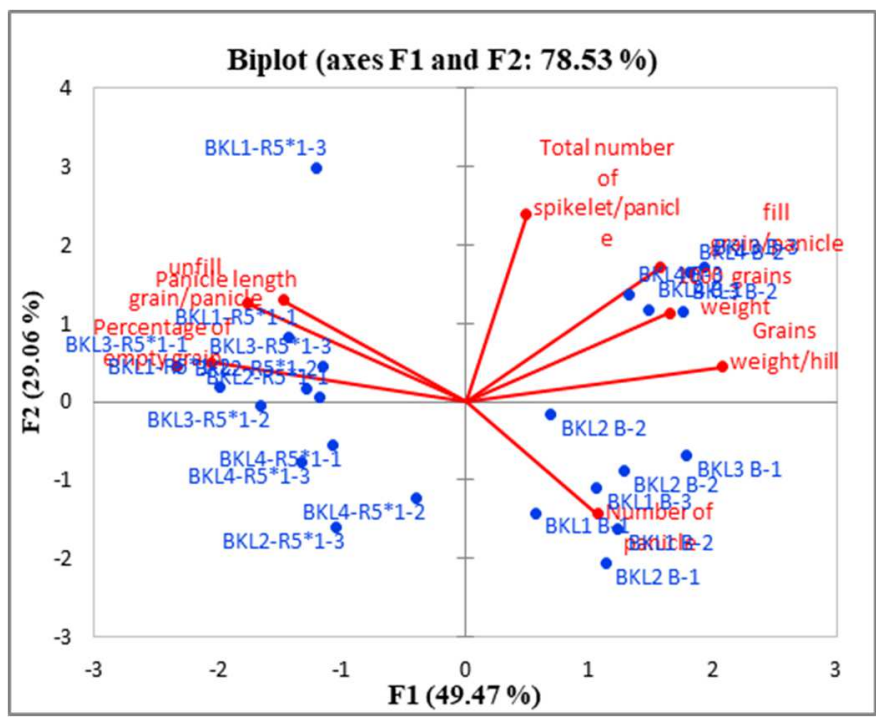

Fig 2. Biplot analysis showing the spreading of yield component and yield traits on genotypes obtained from the crossing.

Fig 2 shows four traits as a Group I Identifier member: the total number of grains per panicle, filled grain per panicle, the weight of 1000 grains, and the weight of grain per hill. The genetic population of the crossing included BKL4-B-2, BKL3-B-3, BKL4-B-3, BKL3-B-2. Group Identifier II was superior in the length of the panicle, the number of empty grains per panicle, and the open grain percentage. Members of these groups included BKL1-RS*1-3, BKL1-RS*1-1, BKL3-RS*1-1, BKL3-RS*1-3, BKL1-RS*1-2, BKL2-RS*12 , and BKL2-RS*1-1. Group Identifier III was superior in the number of panicles found in the next crossing: BKL2-B-2, BKL3-B-1, BKL1-B-1, BKL1-B-2, and BKL2-B-1. A significant positive correlation between each trait in the group has also been demonstrated in Table 3 .

Analysis of the main coordinate was carried out to show each tested line's relative position, as presented in Fig 2. The results demonstrated that the following traits, the total number of grains per panicle, filled grain per panicle, the weight of 1000 grain, weight of grain per hill, had a greater chance to yield a higher population average than the other traits. To improve the yield of new type rice, it needed parental lines with superior grain per panicle length and length of the panicle [24], [28]. One of the ideal traits for new rice is that the number of grain must be 180-240, with the percentage of filled grain about $85 \%$ [27]. A number of filled grain were used as the indicator trait to develop a new type of rice [23], [31]. Besides, an ideal new type of rice must have 150 number of filled grain [23] or 160 number of grain [31]. From this discussion, it may be suggested that the traits of the total number of grain per panicle, filled grain per panicle, the weight of 1000 grain, weight of grain per hill have to be considered while selection for high yield as they expressed positive and significant correlation with grain yield. A positive inter-correlation was also noticed between these traits. Hence, a balance should be maintained while selecting for these traits. It will bring up improvements in the yielding potential and also the traits themselves.

\section{CONCLUSION}

Broad sense genetic diversity was found for the number of traits, such as number of panicles, the total number of grain per panicle, number of empty grain per panicle, number of filled grain per panicle, percentage of empty grain, the weight of 1000 grains, the weight of grain per hill, which potentially improved high yielding. These genotypes were categorized into three groups, each of which had its own characteristics. Group I showed superior traits for the total number of grain per panicle, the number of filled grain per panicle, weight of 1000 grains, and weight of grain per hill found in genotypes BKL4-B-2, BKL3-B-3, BKL4-B-3, BKL3-B-2. Group II had superior traits for panicle length, the number of empty grain per panicle, and the percentage of empty grain were BKL1RS*1-3, BKL1-RS*1-1, BKL3-RS*1-1, BKL3-RS*1-3, BKL1-RS*1-2, BKL2-RS*1-2, and BKL2-RS*1-1. Groups III was superior to the number of panicle traits found in genotypes BKL2-B-2, BKL3-B-1, BKL1-B-1, BKL1-B-2, and BKL2-B-1.

\section{ACKNOWLEDGMENT}

We appreciate the Directorate of Research and Community Service, Ministry of Education and Culture Republic of Indonesia that provided funding through National Strategic Research with Contract Number: 052/SP2H/ LT/DRPM/2018. Also, we are grateful to the Head of Research and Community Board, Dean of the Agricultural Faculty, and Head of the Department of Crop Production at the University of Bengkulu to facilitate this research.

\section{REFERENCES}

[1] B. P. Statistik, "Luas panen, produksi, dan produktifitas padi di Indonesia. 2018.," 2018. https://www.bps.go.id/dynamictable/2019/04/15/1608/luas-panenproduksi-dan-produktivitas-padi-menurut-provinsi-2018.html.

[2] H. M. Toha, "Pengembangan Padi Gogo Mengatasi Rawan Pangan Wilayah Marginal," Prospek Pertanian Lahan Kering dalam Mendukung Ketahanan Pangan. pp. 143-163, 2012, [Online]. Available: http://www.litbang.pertanian.go.id/buku/Lahan-KeringKetahan/BAB-III-4.pdf. 
[3] S. Shah et al., "Genetic analysis of F4:F5 marker assisted derived lines of rice against bacterial leaf blight (BLB) and their marker validation," Vegetos, vol. 30, no. Special Issue 1, pp. 93-100, 2017, doi: 10.5958/2229-4473.2017.00043. X.

[4] R. Herawati, B. S. Purwoko, and N. Khumaida, "Pembentukan Galur Haploid Ganda Padi Gogo dengan Sifat-Sifat Tipe Baru melalui Kultur Antera," J. Agron. Indones. (Indonesian J. Agron., vol. 36, no. 3, pp. 181-187, 2008, doi: 10.24831/jai. v36i3.1375.

[5] A. Hairmansis, Y. Yullianida, S. Supartopo, and S. Suwarno, "Rice improvement for upland areas," Iptek Tanam. Pangan, vol. 11, no. 2, pp. 2017, [On-106, Available: http://www.ejurnal.litbang.pertanian.go.id/index.php/ippan/article/vie w/6078.

[6] A. Mishra et al., "Genetic diversity and population structure analysis of Asian and African aromatic rice (Oryza sativa L.) genotypes," $J$. Genet., vol. 98, no. 3, 2019, doi: 10.1007/s12041-019-1131-0.

[7] M. Hasan-Ud-Daula and U. Sarker, "Variability, heritability, character association, and path coefficient analysis in advanced breeding lines of rice (Oryza sativa L.)," Genetika, vol. 52, no. 2, pp. 711-726, 2020, doi: 10.2298/GENSR2002711H

[8] R. Herawati, Masdar, and Alnopri, "Genetic analysis of grain yield of F4 populations for developing new type of upland rice," Sabrao J. Breed. Genet., vol. 51, no. 1, pp. 68-79, 2019.

[9] M. D. Asante, K. L. Adjah, and E. Annan-Afful, "Assessment of Genetic Diversity for Grain Yield and Yield Component Traits in Some Genotypes of Rice (Oryza Sativa L.)," J. Crop Sci. Biotechnol., vol. 22 , no. 2 , pp. 123-130, 2019, doi: 10.1007/s12892-019-0008-0.

[10] U. Bhattarai and P. K. Subudhi, "Genetic diversity, population structure, and marker-trait association for drought tolerance in US rice germplasm," Plants, vol. 8, no. 12,2019, doi: 10.3390/plants8120530.

[11] T. Guru et al., "Genetic diversity analysis for yield attributing traits in rice genotypes," Res. Crop., vol. 18, no. 2, pp. 311-315, 2017, doi: 10.5958/2348-7542.2017.00053.5

[12] R. Donde et al., "Assessment of Genetic Diversity of Drought Tolerant and Susceptible Rice Genotypes Using Microsatellite Markers," Rice Sci., vol. 26, no. 4, pp. 239-247, 2019, doi: 10.1016/j.rsci.2019.01.004.

[13] R. Anupriya, S. Geetha, D. Rajakumar, S. A. Senthil, S. Thankappan, and A. K. Binodh, "Clustering and principal component analysis of traditional rice landraces grown under in vitro moisture stress condition," Plant Cell Biotechnol. Mol. Biol., vol. 21, no. 42, pp. 5160, 2020.

[14] P. Sharifi, M. Mohammadi, and R. Karimizadeh, "Biplot analysis of diallel crosses for yield and some of morphological traits in wheat," Vegetos, vol. 32, no. 3, pp. 420-430, 2019, doi: 10.1007/s42535-01900046-z.

[15] Stanfield William D, Theory and Problems of Genetics, Third Edit. Graw Hill Book Co. New Delhi: McGraw-Hill, 1983.

[16] B. Singh, R.K. and Chaudhury, Biometrical method in quantitative genetic analysis. India: Kalyani, 1985.

[17] R. Herawati, B. S. Purwoko, and I. S. Dewi, "Characterization of Doubled Haploid Derived from AntherCulture for New Type Upland Rice," vol. 38, no. 3, pp. 170-176, 2010.

[18] M. Reny Herawati, Entang Inoriah, Rustikawati, "Genetics Diversity and Agronomic Characters of F3 Lines Selected by Recurrent Selection for Drought Tolerance and Blast Resistance of Bengkulu
Local Rice Varieties," Int. J. Adv. Sci. Eng. Inf. Technol., vol. 7, no. 3, pp. 922-927, 2017, doi: http://ijaseit.insightsociety.org/index.php?option=com_content\&view $=$ article\&id=9\&Itemid=1\&article_id=1641.

[19] P. Bisen et al., "Genetic analysis and trait association for yield related traits in F2:3 biparental population of rice under slightly sodic condition," Electron. J. Plant Breed., vol. 10, no. 3, pp. 1105-1112, 2019, doi: 10.5958/0975-928X.2019.00141.8

[20] H. M. Sarif et al., "Genetic diversity and variability among pigmented rice germplasm using molecular marker and morphological traits," Biotechnol. Biotechnol. Equip., vol. 34, no. 1, pp. 747-762, 2020, doi: 10.1080/13102818.2020.1804451.

[21] R. S. Sabri, M. Y. Rafii, M. R. Ismail, O. Yusuff, S. C. Chukwu, and N. Hasan, "Assessment of agro-morphologic performance, genetic parameters and clustering pattern of newly developed blast resistan rice lines tested in four environments," Agronomy, vol. 10, no. 8, 2020 , doi: 10.3390/agronomy10081098.

[22] F. Wang and S. bing Peng, "Yield potential and nitrogen use efficiency of China's super rice," J. Integr. Agric., vol. 16, no. 5, pp. 1000-1008, 2017, doi: 10.1016/S2095-3119(16)61561-7.

[23] S. Peng, R. C. Laza, R. M. Visperas, G. S. Khush, P. Virk, and D. Zhu, "Rice: Progress in Breaking the Yield Ceiling," Proc. 4th Int. Crop Sci. Congr., no. Chandler 1982, pp. 1-11, 2004, [Online]. Available: http://www.cropscience.org.au/icsc2004/pdf/982_pengs.pdf.

[24] M. Huang, Q. yuan Tang, H. jun Ao, and Y. bin Zou, "Yield potential and stability in super hybrid rice and its production strategies," $J$. Integr. Agric., vol. 16, no. 5, pp. 1009-1017, 2017, doi: 10.1016/S2095-3119(16)61535-6.

[25] G. Li et al., "Limitation of unloading in the developing grains is a possible cause responsible for low stem non-structural carbohydrate translocation and poor grain yield formation in rice through verification of recombinant inbred lines," Front. Plant Sci., vol. 8, no. August, pp. 1-16, 2017, doi: 10.3389/fpls.2017.01369.

[26] B. Abdullah, I. S. Dewi, H. Safitri, and A. P, "Perakitan Padi Tipe Baru Melalui Seleksi Silang Berulang dan Kultur Anter," Penelit. Pertan. Tanam. Pangan, vol. 27, no. 1, pp. 1-8, 2008.

[27] J. long BIAN et al., "Comparative analysis on grain quality and yield of different panicle weight indica-japonica hybrid rice (Oryza sativa L.) cultivars," J. Integr. Agric., vol. 19, no. 4, pp. 999-1009, 2020, doi: 10.1016/S2095-3119(19)62798-X.

[28] R. Li, M. Li, U. Ashraf, S. Liu, and J. Zhang, "Exploring the relationships between yield and yield-related traits for rice varieties released in china from 1978 to 2017," Front. Plant Sci., vol. 10, no. May 2019, doi: 10.3389/fpls.2019.00543.

[29] K. Das et al., "Grain density and its impact on grain filling characteristic of rice: Mechanistic testing of the concept in genetically related cultivars," Sci. Rep., vol. 8, no. 1, pp. 1-11, 2018, doi 10.1038/s41598-018-22256-2.

[30] A. H. Jarwar et al., "Genetic Divergence on The Basis of Principal Component, Correlation and Cluster Analysis Of Yield And Quality Traits In Cotton Cultivars," Pak. J. Bot, vol. 51, no. 3, pp. 1143-1148, 2019.

[31] Z. $\mathrm{Xu}, \mathrm{W}$. Chen, L. Zhang, and S. Yang, "Design principles and parameters of rice ideal panicle type," Chinese Sci. Bull., vol. 50, no. 19, pp. 2253-2256, 2005, doi: 10.1360/982005-952. 